\title{
THE INFLUENCE OF WEATHER ON THE INFLAM- MABILITY OF FOREST FIRE FUELS
}

\section{By J. G. WRIGHT}

$\mathrm{I}^{\mathrm{I}}$ T has long been recognized by all who have come in contact with the forest that certain weather factors exert a controlling influence on the oc. currence of forest fires. Occasionally, in a bad fire year, one may see news items in the press which would lead one to believe that fires just happen like Spanish influenza, but no forest fire ever assumed any proportions without a preceding period of dry weather and a starting agency to apply the necessary heat for ignition. Lightning is the only weather factor which may act as an ingnition agent, but unless the forest is dry enough, fire will not spread even from a lightning stroke.

A forest fire, like any other fire, is a chemical action which follows certain known laws. The fuel consists largely of carbon and perhaps certain resinous oils. The temperature of this fuel must be raised by the ignition agent to the kindling temperature where the carbon will combine with the oxygen of the air resulting in combustion. If the heat generated by the combustion of the fuel at the point of ignition is great enough to raise the temperature of the adjacent fuel to the kindling point, the fire will spread. If not, it will go out as soon as the heat supplied by the ignition agent is removed. The more moisture there is in the fuel, the more heat will be required to raise it to the ignition or kindling temperature, until a point is reached where due to the quantity of moisture present in the fuel, fire will not spread. It will be seen, therefore, that the moisture content of a fuel determines its behaviour in the presence of a potential source of ignition, and if the weather factors which influence this moisture content can be isolated and measured, it should be possible to determine the inflammability of the fuel under given weather conditions; in other words, to build up a chart from day to day showing the cumulative effect of the weather upon the fire hazard.

So far as has been ascertained, it would appear that the first attempt in Canada to construct a fire hazard chart based upon the weather was begun about 1916 by the present Director of Forestry, Mr. E. H. Finlayson, then District Forest Inspector for Alberta. It was recognized that rainfall, temperature, and wind exerted an important influence on the moisture content of forest fire fuels. These factors were given weights and plotted on a chart from day to day and served as a valuable guide as to the inflammability of the forest.

About this time and during the following few years, considerable investigation was carried on which brought out the fact that the relative humidity of the air was an important factor. Most forest fire fuels are hygroscopic, 

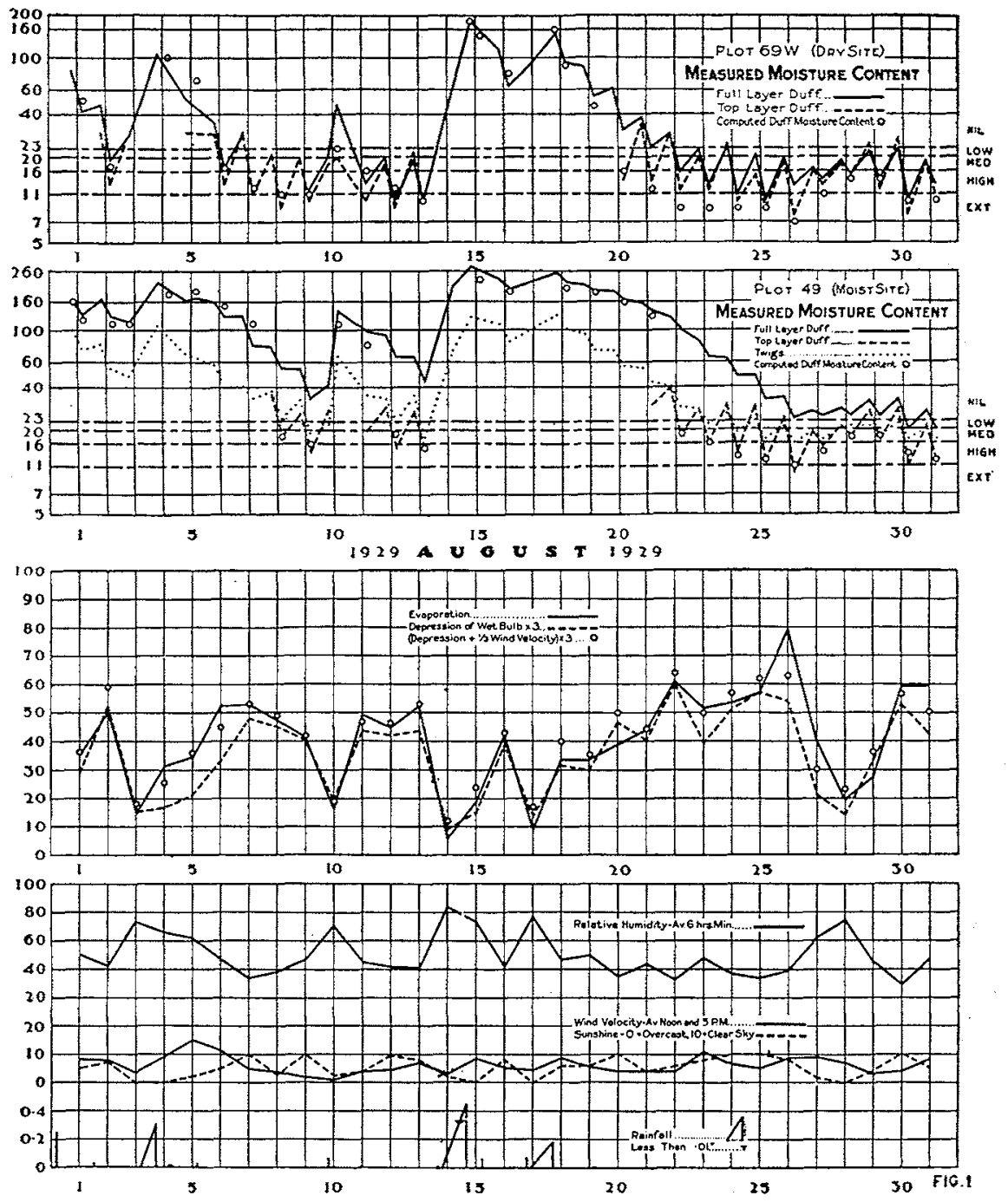

that is, they will absorb moisture from the air if the relative humidity is high and give it up to the air when the relative humidity drops. For each relative humidity there is a point of equilibrium moisture content for each fuel which will be reached if the humidity is sustained long enough, and at which the moisture content of the fuel will remain stationary. If the humidity rises, the fuel will take on moisture and establish a new equilibrium corresponding to the higher humidity. If the humidity drops, the moisture content will drop accordingly. What is here said relates to sustained humidities which in reality can only be attained in the laboratory. Actually, in the field, the 
fuels seldom reach true equilibrium due to the changing conditions from day to day and between day and night. However, it has been found from studies conducted during the past summer that certain states of what may be called "Field equilibrium" are reached, in which the moisture taken up by the fuels at night balances the moisture given off during the day. This will be illustrated by means of charts further on.

Much good work has been done in correlating relative humidity with the occurrence of fires. In the absence, of course, of rain, certain humidities have been declared safe and others dangerous. In the Pacific Coast states any humidity below 30 per cent. has been said to be dangerous. In Eastern Canada, 50 per cent. is usually taken as the danger line; that is, few fresh fires have been found to start with the humidity above that point. While very good correlation has usually been found between certain relative humidities and the occurrence of fires, most investigators have encountered inconsistencies which they have found difficult to explain, and some have mis. takenly come to the conclusion that relative humidity records are not of very great value. The difficulty, as we shall see presently, is that those who use humidity records alone have not been taking account of certain other important weather factors which must be considered in making intelligent use of humidity records.

\section{PURPOSE OF STUDIES}

The purpose of the past season's fire weather work at the Petawawa Forest Experiment Station was to make a critical study of the effect of all weather factors influencing the moisture content of certain forest fuels in which fires start or spread. The purpose was also to determine the rate of drying of these fuels under different weather conditions with a view to translating daily weather records into terms of fire hazard and constructing a fire hazard chart. So far as is known this is the first attempt which has been made to attach definite time values to the effect of weather factors.

\section{METHOD OF PROCEDURE}

Every weather factor which could possibly enter into the question was measured, namely, rainfall, temperature, relative humidity, depression of the wet bulb of the sling psychrometer, wind velocity, evaporation, sunshine, and barometric pressure.

The fuels in three different sites in mixed red (P. Resinosa) and white (P. Strobus) pine were studied as follows:--

(1) Plot 49. Nearly full canopy, mixed red and white pine, 4 in. to 10 in. in diameter, on nearly level, sandy land. This may be considered as a moist site. The potential ignition fuels on this site consisted of about $1 \frac{1}{4}$ in. to $11 / 2$ in. of duff with needles in the bottom layers well 


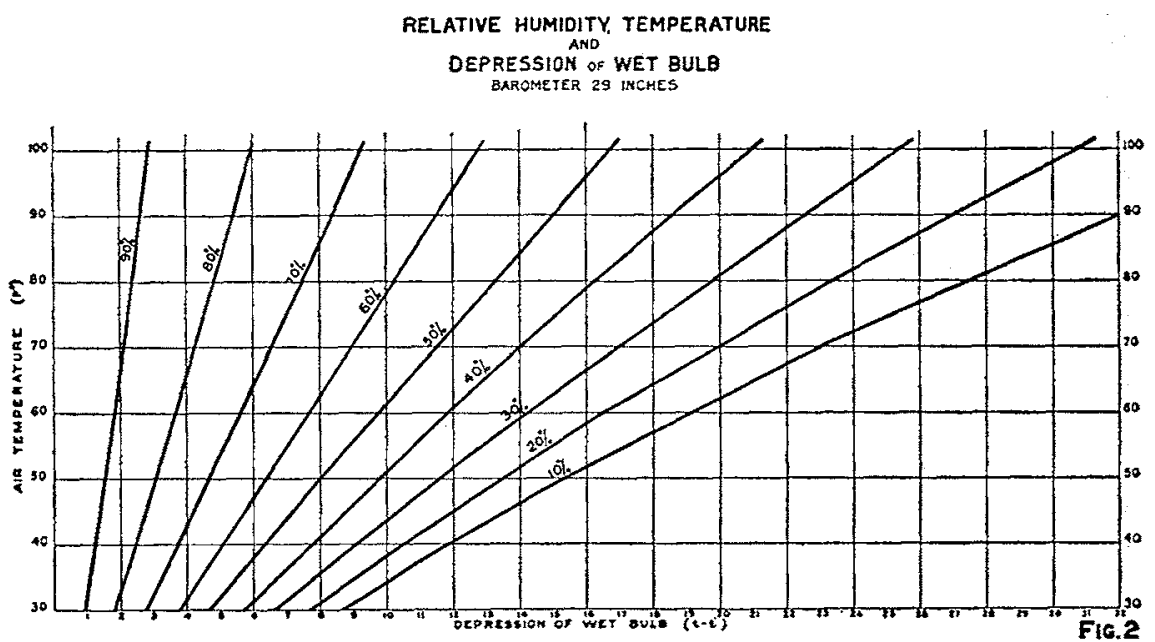

broken down by decay, and a scattering of dead, fallen twigs and branches.

(2) Plot 69. About $1 / 2$ canopy mixed red and white pine with an occasional hardwood on sandy soil, with occasional rock outcrops. This may be termed a medium site. The ignition fuels here consisted of about 1 in. of duff, fallen twigs and branches, pine needles on dead, fallen trees, and bracken, which in the spring and fall is an important ignition fuel.

(3) Plot $69 \mathrm{~W}$. This site was under red and white pine on light, sandy soil, on the edge of an open northwest slope. The site was exposed to the afternoon sun and to all wind from north to west. It may be consid. ered as a dry site. The chief ignition fuel here was slightly over one inch of duff, the bottom layers of which were not decayed as in the moist site. Some dead, fallen twigs and branches were also present.

The moisture content of the full layers of duff based upon the oven dry weight was determined by weighing twice daily a section of undisturbed duff, 16 in. $\times 24$ in., which rested in its natural position in an open wire tray or basket lined with cheesecloth. These readings were repeatedly checked by oven drying similar samples taken nearby. The oven dry weight of the tray of duff was determined at the end of the season.

The moisture content of the top layer of duff $(1 / 4$ in. to $1 / 2$ in.) was measured with the duff hygrometer and repeatedly checked by oven dried samples. At this point it may be mentioned that a difficulty hitherto met with in the use of the duff hygrometer was successfully overcome. The topmost half inch of duff is the layer in which fires start or spread, particularly in moist full canopy sites where the lower layers of duff are partially decom- 
posed. These lower layers of decayed litter hold moisture long after the top layer has dried out to inflammability and owing to the influence of this lower duff moisture, difficulty was experienced in placing the hygrometer so that it would correctly register the moisture content of the top layer. This was overcome by placing the duff hygrometer tube barely under the surface and covering it with about one half inch of top layer duff gathered nearby. Very consistent results were obtained from this method of placing the hy. grometer.

The rattan duff hygrometer at best will not register moisture content above 50 per cent. The ones used during the past season could not be relied upon above 30 per cent. which, however, it will be seen later is well above the inflammable range. The duff moisture content may, however, rise to nearly 300 per cent. of the oven dry weight of the duff following a rain. Moisture contents as high as 284 per cent. were recorded during the past season and it was to cover this wide range that the basket or tray method was resorted to in addition to the duff hygrometer. The main objections to using the basket method alone are:-

(1) The difficulty of securing comparable sample baskets; the moisture of the sample being noticeably influenced by the thickness of the duff and the extent to which the lower layers are decayed.

(2) The fall of fresh needles on to the sample basket introduced an error which can be overcome only in part.

(3) The full duff layer in the sample basket usually does not reach inflammability for some time after the top layer is inflammable. This time lag cannot be allowed for as it varies greatly.

The moisture content of twigs up to $1 / 2$ in. was measured in two ways. First, by weighing a basket of twigs which rested on the duff. This would represent the scattered twigs lying in contact with the duff. Second, by weighing a suspended wire cylinder to which twigs were tied. This would represent twigs on fallen branches out of contact with the ground.

The moisture content of bracken was measured by weighing a suspended basket of this material.

The next step was to determine the ranges of inflammability corresponding to different moisture contents of the fuels. This was done by repeated burning tests with matches, cigarette butts and camp-fires. Five zones of mixed red and white pine duff inflammability were established as follows:-

Zone

Non-Inflammable

Low-Inflammability

Medium Inflammability

High Inflammability

Extreme Inflammability
Top Layer Duff Moisture Content

Over $23 \%$

$23 \%$ to $20 \%$

$20 \%$ to $16 \%$

$16 \%$ to $11 \%$

$11 \%$ or lower 


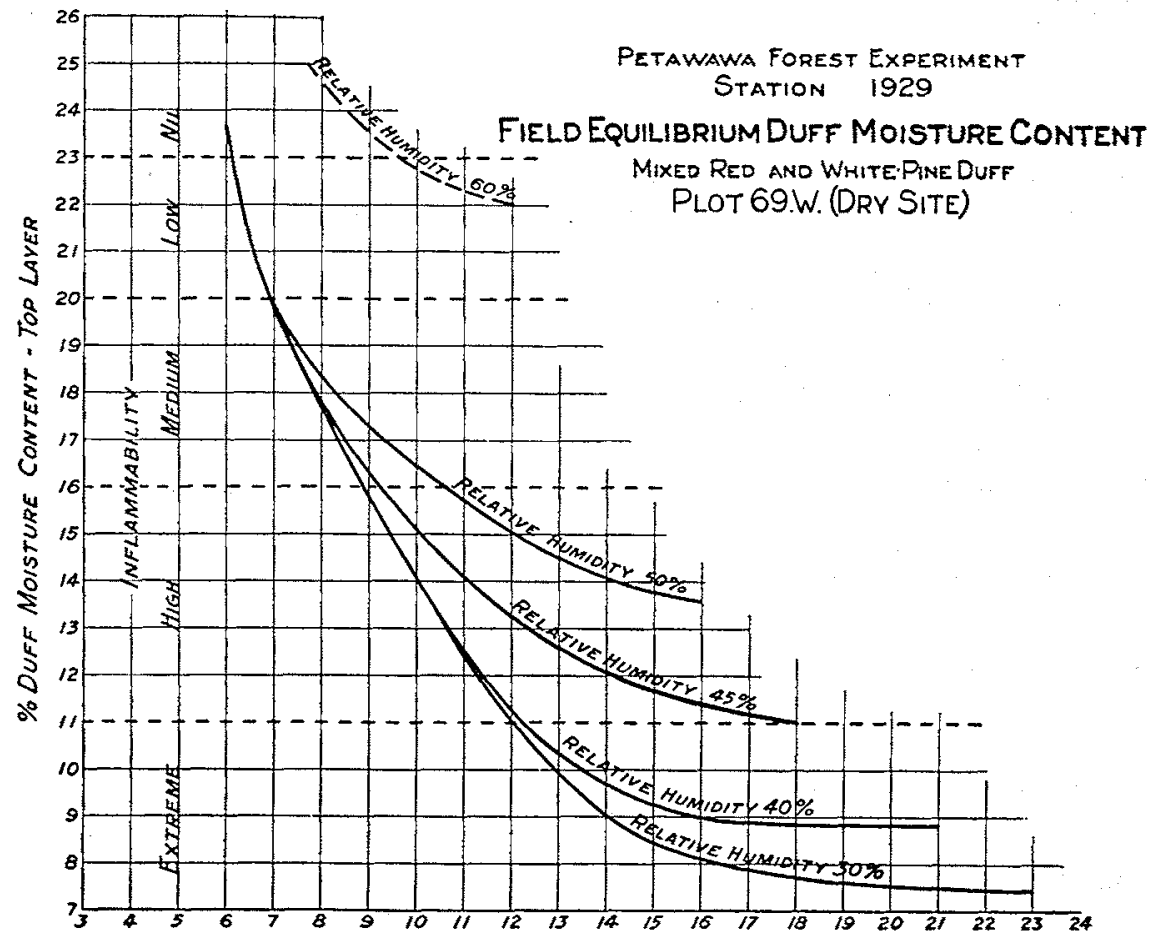

DEPRESSION OF WET BULB. $\left(t-t^{\prime}\right)$

FiG.3

With over 20 per cent duff moisture content, a match invariably failed to start a fire which would not go out by itself. Small campfires were effective in starting fires up to 21.5 per cent. With any moisture content below 20 per cent, a dropped match proved a potential source of fire, although ignition could not be considered certain above 17 or 18 per cent. Cigarette butts proved a negative source of fire in mixed red and white pine duff except in the zone of extreme inflammability.

The limit of match inflammability for bracken was slightly below 23 per cent moisture content which puts it in the same range as duff.

Twigs in contact with the duff were found to be at almost the same state of inflammability as the duff. Generally speaking if the duff will burn the smaller twigs will burn.

Some interesting laboratory data is being obtained on the ignition temperatures of the different fueis which will be included in a later report. It might be pointed out here, however, that it appears that pure red pine duff is considerably more inflammable than white pine and the foregoing remarks apply to mixed red and white pine or an average of the two. This should be borne in mind in making use of the data submitted. 
The past season's work indicates the necessity for independent studies in each type of forest and for each climatic area.

\section{ANALYSIS OF DATA}

We now come to the analysis of the data collected. On the chart shown in Fig. 1, we have plotted the records for the month of August, for illustration.

The top graph shows the moisture content of the full layer and top layer of mixed red and white pine duff for the dry site. The full layer is shown by a solid line and the top layer by dashes.

The second graph shows the moisture content of the full layer of duff by a solid line, the top layer by dashes, and twigs up to $1 / 2$ in. by a dotted line for the moist site. The inflammability zones are shown on these graphs by long-and-short-dash horizontal lines.

The third graph shows the evaporation for each day as measured by a Livingstone porous cup atmometer. The same graph also shows the depres. sion of the wet bulb for the average six hours' minimum humidity for each day.

The fourth graph shows the average six hours' minimum humidity for each day. The average six hour minimum was taken as this was found to eliminate sharp dips which did not last long enough to have much effect. The average six hour minimum thus provides a better criterion of the effect of humidity than a single minimum.

The fifth graph shows the average wind velocity for noon and 5 p.m. readings, and sunshine on the scale of zero equals overcast and ten equals clear sky.

The bottom graph shows the amount and duration of rainfall.

Temperature and barometric pressure were also measured, but are not shown here because, as we shall see later, temperature is taken care of by the depression of the wet bulb, and the barometer was only used in forecasting weather changes.

\section{DEPRESSION AND EVIAPORATION}

The first thing to be observed is that the curve showing the depression of the wet bulb follows very closely the evaporation curve, the principal points of difference being due to wind. If we take one third of the wind velocity and add it to the depression, we get a curve indicated by circles on the evaporation graph, which follows still more closely the evaporation curve. This assumed rule of taking one third the wind velocity has not been tried out for velocities above 15 miles per hour which was the highest mean noon and 5 p.m. velocity observed. 


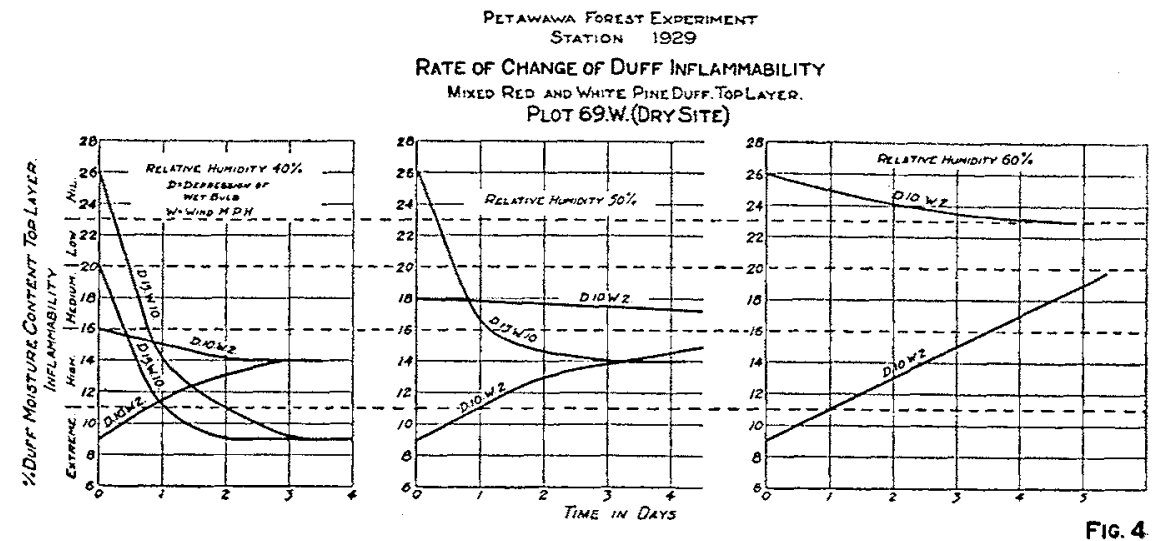

\section{RELATIVE HUMIDITY AND DEPRESSION}

Having shown that the depression of the wet bulb is a fair indication of the rate of evaporation and when one third the wind velocity is added it is still more nearly correct, let us look at a chart (Fig. 2) showing the relation between relative humidity, temperature, and depression of the wet bulb. Relative humidity is, of course, a function of air temperature and depression of the wet bulb. Looking at the chart it will be observed that a wet bulb depression of 12 degrees gives a humidity of 20 per cent with an air temperature of 45 degrees, 40 per cent at 60.5 degrees, 50 per cent at 73 degrees, and 60 per cent at 94 degrees, and the rate of evaporation will be practically the same in each case. In other words, drying will be just as rapid with: a humidity of 60 per cent and a temperature of 94 degrees as it is with a humidity of 20 per cent and a temperature of 45 degrees. We shall see later that drying goes on fast enough to be dangerous with any depression above 10 degrees. It, therefore, follows that a humidity of 50 per cent becomes increasingly dangerous as the temperature rises above 60 degrees, and a humidity of even 60 per cent. may become dangerous when the temperature rises above 80 degrees.

This chart was devised to illustrate the foregoing points, but reduced to pocket size it should prove very convenient instead of tables for determining the relative humidity obtained with a sling psychrometer.

\section{FIELD EQUILIBRIUM}

We now come to a chart (Fig. 3) showing the effect of relative humidity and depression of the wet bulb on red and white pine duff at the dry site in establishing a "field equilibrium" moisture content. Going back to the chart showing the duff moisture content for August (Fig. 1), we see that after the effect of rain has passed off, the duff takes on moisture at night 
and gives it off during the day. In this region the relative humidity almost invariably rises to a high value at night, usually to nearly $100 \%$. "Field equilibrium" may be defined as a condition in which the moisture given off during the day just balances that taken up during the night, so that there is no further net loss in weight from day to day. It will be readily seen that this field equilibrium depends not so much on humidity alone as in the case of a laboratory equilibrium, but principally upon the rate of evaporation which has been shown to be proportional to the depression of the wet bulb.

The curve on the chart (Fig. 3) shows the field equilibrium moisture content dropping as the depression of the wet bulb increases. Relative humidity does also enter into the case because as the moisture content approaches the true equilibrium for a particular humidity, the curve branches off from the main curve and gradually flattens out. Laboratory determination of equilibrium moisture content for all fuels studied is at present under way, but the results are not yet available. It will, however, probably be found that the true equilibriums for the humidities shown on the chart are considerably lower than the flat parts of the curves. Nevertheless, as the moisture content approaches the true equilibrium, the rate of drying decreases irrespective of the depression of the wet bulb, until the field equilibrium is established, and there is no further net loss in moisture.

A similar chart has been prepared for the moist site. This shows the field equilibrium established at a slightly higher moisture content as would be expected because duff at the moist site retains moisture more readily.

\section{RATE OF CHANGE OF INFLAMMABILITY}

We will now pass on to a chart (Fig. 4) showing the rate of change of duff inflammability at the dry site under different conditions of humidity and depression of the wet bulb. From this chart we can determine the probable moisture content which will be reached at the end of one, two, three or more days with the humidities and depressions shown. It is interesting to note that with a humidity even as low as 40 per cent accompanied by low depres. sion and low wind velocity, the duff will take on some moisture.

At 50 per cent humidity with a depression of 15 and wind velocity of 10 M.P.H., the duff will dry out at the rate and to the point shown. With a depression of 10 or less and low wind velocity, however, there will be little loss in weight at higher moistures, and at low moisture the duff will take on weight. At 60 per cent humidity the effect of low depression is even more marked.

A similar chart was prepared for the moist site which is substantially the same as the one illustrated, except that the curves are flatter, indicating slower drying. 

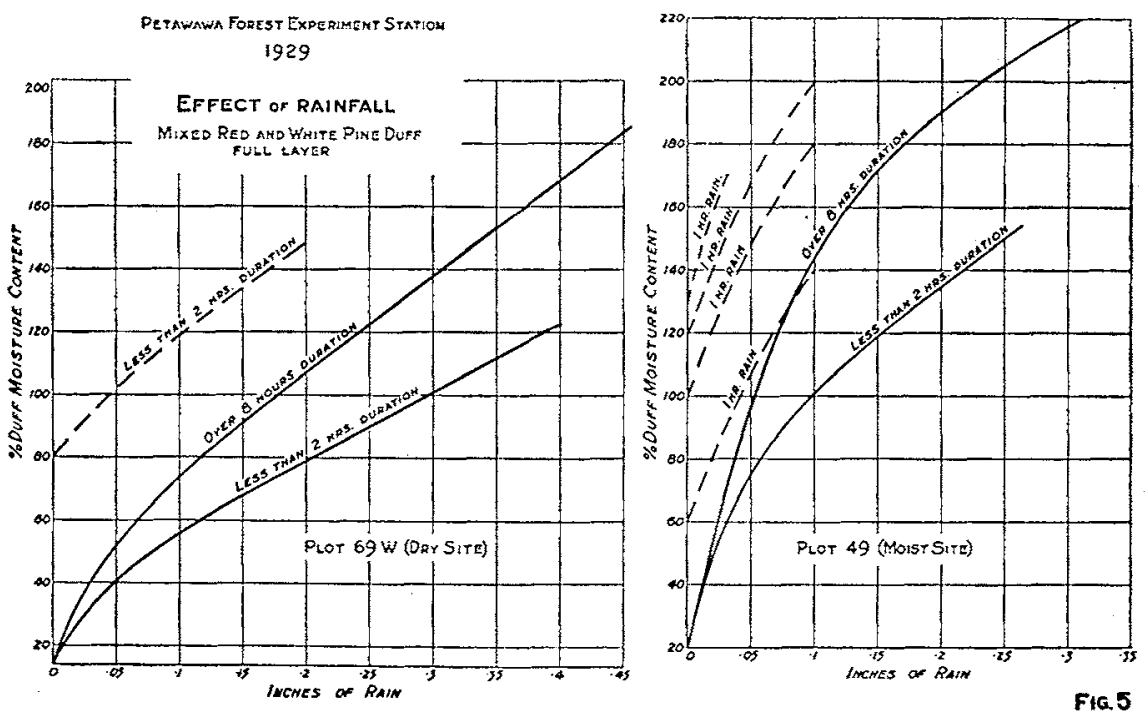

\section{EFFECT OF RAINFALL}

We may now pass on to a chart (Fig. 5) showing the effect of rainfall in adding moisture to the duff at the dry site and also at the moist site. This shows the approximate moisture content to which different amounts of rain will raise the full layer of duff. In passing we may note that the effect of rain is much more pronounced in the moist site due to the facility with which the decomposed litter in the lower layers of duff absorbs the moisture.

\section{RATE OF DRYING AFTER RAIN}

We now come to a graph (Fig. 6) showing the rate of drying after rain at the dry site. At this site the effect of wind was quite pronounced in accelerating the rate of drying following rain. We can, therefore, use the rule of adding one-third the wind velocity to the depression of the wet bulb. The upper set of curves show the rate at which the full layer of duff dried out from different moisture contents. The numbers on the curves indicate the condition of humidity and depression plus one-third wind velocity which accompanied the drying.

Depression of the wet bulb and wind velocity govern the rate of drying until we get down to the lower moisture where we approach the equilibrium point for humidities of 60 per cent and over. In this vicinity we must consider the humidity as well as the depression. For example, Curve $\mathrm{F}$ with a humidity of 60 per cent. and a depression plus one-third wind velocity of 9 , begins to flatten out and never reaches inflammability. If the humidity 
had been, say, 40 per cent., with the same depression, the curve would prob. ably not have flattened out so much.

The lower set of curves show the rate at which the top layer of duff reaches inflammability. Here again, relative humidity is important because a high humidity may hold the top layer above the inflammability point, while drying of the full layer is still going on.

A similar set of curves were prepared for the moist site. These differ from the ones illustrated mainly in that the rate of drying is slower. Also, wind velocity has little effect in the full canopy moist site. It was found that in the average the wind velocity under the full canopy was only one-tenth that in the open.

\section{PRACTICAL APPLICATION OF CHARTS}

We are now in a position to make a practical use of the charts entitled "Effect of Rainfall" (Fig. 5), "Rate of Drying after Rain" (Fig. 6), and "Rate of Change of Inflammability" (Fig. 4), in computing the daily fire hazard from the weather records alone. Let us start with a rain following a period where the duff moisture content is approximately known such as after a moderately dry spell when it is somewhere in the region of inflammability. Knowing the amount of rain which has fallen, we determine from the Effect of Rainfall chart (Fig. 5) the probable moisture content which will be produced by this rain.

We then take the Rate of Drying chart (Fig. 6) and knowing the humidity, wind velocity, and depression of the wet bulb on the days following the rain, we interpolate on the chart to find the drying effect of these factors. For instance, if we find that the rain raised the moisture content to around 160 per cent. and the humidity and depression plus one-third wind velocity correspond approximately to Curve $\mathrm{D}$, the moisture content of the full layer will have fallen to approximately 45 per cent. at the end of the second day following the rain and the top layer will be just into the inflammability range.

As soon as we find that the top layer is inflammable we can discard the Rate of Drying chart and use the Rate of Change of Inflammability chart (Fig. 4). From this chart we can interpolate the inflammability which occurs each day, knowing the necessary weather factors.

\section{ILLUSTRATION}

The three charts used were compiled from records from May to the end of September. They, therefore, do not favour any one month but are rather averaged for the whole season. As a check on these curves and by way of illustration we have computed from the weather records by the use of the charts the probable hazard for the month of August. The computed moisture 


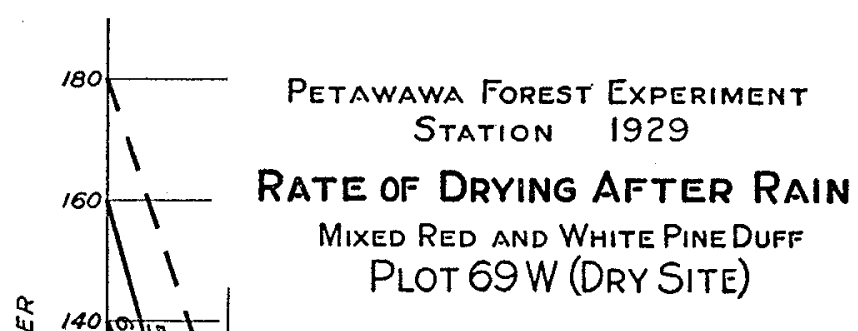

LEgend $-60-9$ = Relative humidity DF $60 \%$ WITH DEPRESSION OF WET BULB PLUS 1/3WIND VELOCITY 99 WIND VELOCITY = AVERAGE OF NOON ANO 5 P.M. READINGS. RELATIVE HUMIOITY: AV. 6 HRS. MiN. DEPRESSION = AV. FOR AgOVE. 6 HRS.
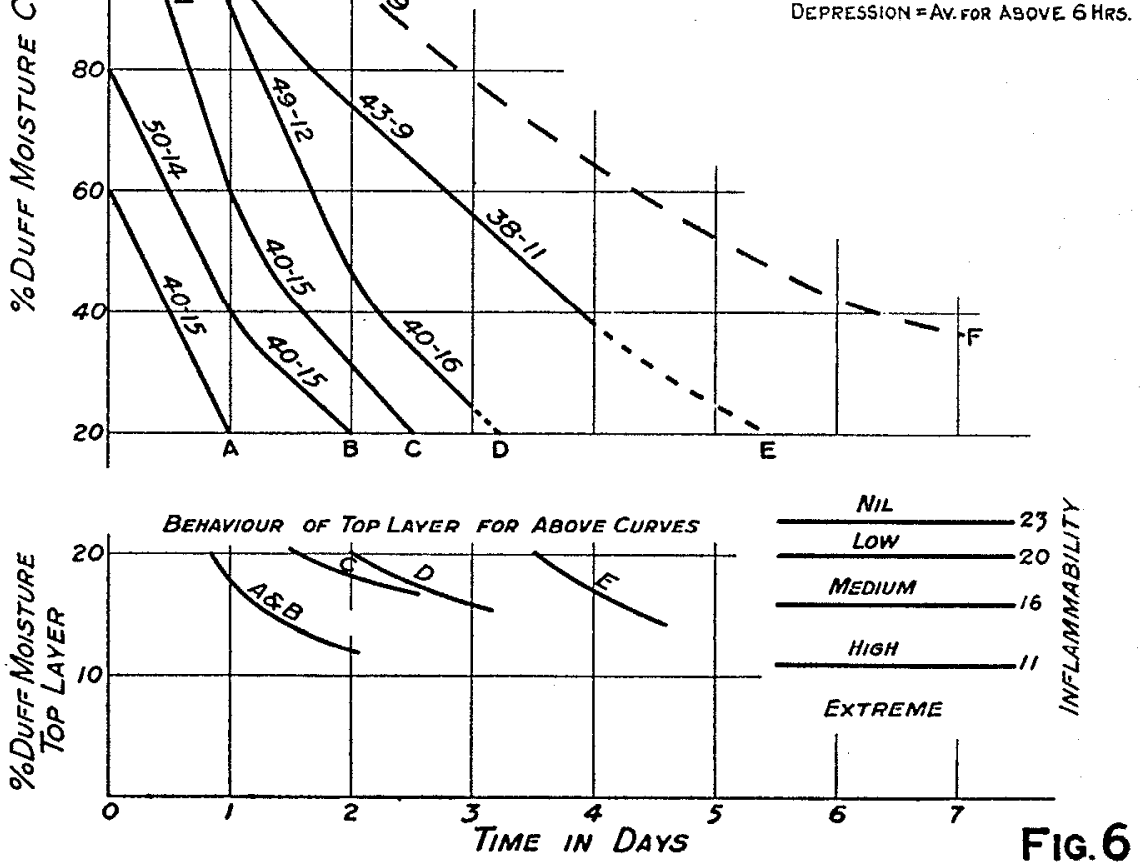

content for each day is shown by a circle on the graph for the dry site (Fig, 1). The same has been done for the moist site. While the results are not perfect by any means, they would, in the absence of actual moisture content measurements, serve as a fair guide to the hazard which existed from day to day.

In developing a computed fire hazard chart by this method, it would be 
well to check results every ten days or so and a few days after a heavy rain by endeavouring to ignite the duff with a match. If fire will spread without going out, the moisture content of the top layer is under 20 per cent. If the fire goes out it may be safely assumed that the moisture content is over 20 per cent. In the example shown the computation was made for the whole month without a check from the graph.

Before we leave the three charts used in computing fire hazard it would be well to emphasize certain points.

(a) They were developed for mixed red and white pine in the climatic conditions existing at the Petawawa Forest Experiment Station.

(b) They are based only on the records of one season and that a rather abnormal one, due to the unusually low rainfall.

(c) They are intended only as a guide to indicate what may be accomplished when fuller records are available.

\section{FIRE HAZARD AND FIRES}

It will be interesting to compare the fire hazard as determined experimentally from day to day during the past season with fires as they actually occurred. We have shown that four zones of inflammability or fire hazard have been established for mixed red and white pine. No fires originated in this type during the past season, but this was only due to the fact that no starting agencies were present at the periods of inflammability. However, numerous fires did occur in other types, and these, together with the measured fire hazard, have been plotted on the graph entitled, "Fire Hazard and Fires" (Fig. 7).

Most of these fires started in open, grassy types. In these types the grass, bracken and other perennial plants are important ignition fuels before the new growth comes up and again after the new growth has dried out. During the past season the only period when these fuels were not likely to burn was from about June 1 st to July 15 th. The unusually dry summer caused these fuels to wither and dry out shortly after the middle of July.

It will be observed from the chart that there is a very close relation between the fires which occurred and the measured hazard in the dry site which is shown by the full line. Seven out of ten fires occurred when the hazard was designated "Extreme." Of the remaining three fires, two occurred well down in the "High" zone and the other just above "High." It is worthy of note that the last fire in September occurred at the time when the duff in the moist site was above the inflammability point, although the hazard in the dry site was "High." In fact the hazard at this period probably went to "Extreme" as there was no rain and the drying conditions were favourable. The moisture content records for the period are missing because the observer was absent making a study of the behaviour of the fire. The gap has been 
FIRE HAZARD AMD FIRES

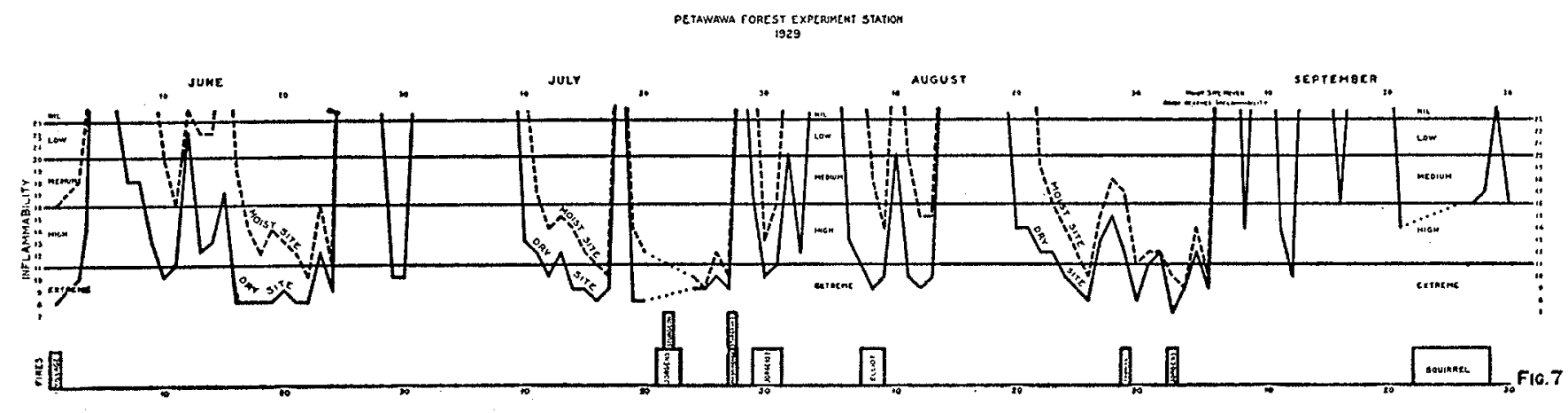

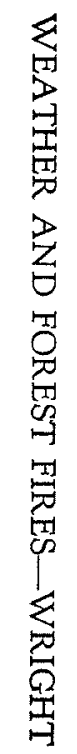


bridged by the dotted line. In passing it may be noted that observations at the fire in question more or less confirmed the conclusions of Show of California that other conditions being equal, the rate of spread of fire varies as the square of the wind velocity.

It is needless to point out to this gathering all the advantages of having a knowledge of the fire hazard which exists from day to day. One respect in which it was found extremely useful at Petawawa during the past season was in detailing the work of the men so that they would be available without delay in the event of a fire being reported. When the hazard warranted, enough men were kept on duty Sundays to serve in case of an emergency.

A large notice board was erected on the Provincial Highway passing through the reserve. On this board was posted daily the hazard which existed on that date with an appropriate warning to persons entering the reserve. There is, of course, no means of knowing what effect this notice board had on the public, but it was at least good publicity and no doubt helped to impress the fact that fire hazard varies from day to day and that special care is necessary at certain times.

In closing there may be mentioned one possible use of an accurate fire hazard chart in certain areas, particularly forest reserves and privately controlled lands, which, if adopted, would practically wipe out 'man-caused' fires. If it had been found possible or expedient to apply and enforce a travel permit system in the Petawawa District last summer and close the areas to travel by refusing permits on the comparatively few days even in a dry summer when the hazard reached "Extreme," only two fires would have occurred. If travel had been forbidden for the slightly longer periods when the hazard was at "High," no fires would have occurred at all. The apparent exception, of a fire which is shown as starting in the zone of "Medium" hazard, does not invalidate this statement because it shows a fire already burning under control which required action on that date to maintain control.

It is recognized that there are several valid objections which may be raised to closing areas to travel. Nevertheless there are times when fires will surely start even in spite of the best care on the part of the public if they are admitted to the forest. Closing the forest to travel at such times seems to be the only sure way of preventing such fires.

\section{SUMMARY}

Summarizing briefly, the following points have been brought out:-

(1) A technique has been developed for measuring forest fire hazard.

(2) It has been shown that depression of the wet bulb plus one-third wind velocity up to 15 M.P.H. may be taken as an approximate measure of the rate of evaporation. 
(3) Rate of drying depends first on depression of the wet bulb, and, second, upon relative humidity.

(4) Curves have been developed showing the effect of the weather factors on the moisture content of duff.

(5) By the use of these curves it is possible to compute from the weather records with a reasonable degree of accuracy, the degree of fire hazard which exists in the type of forest under consideration.

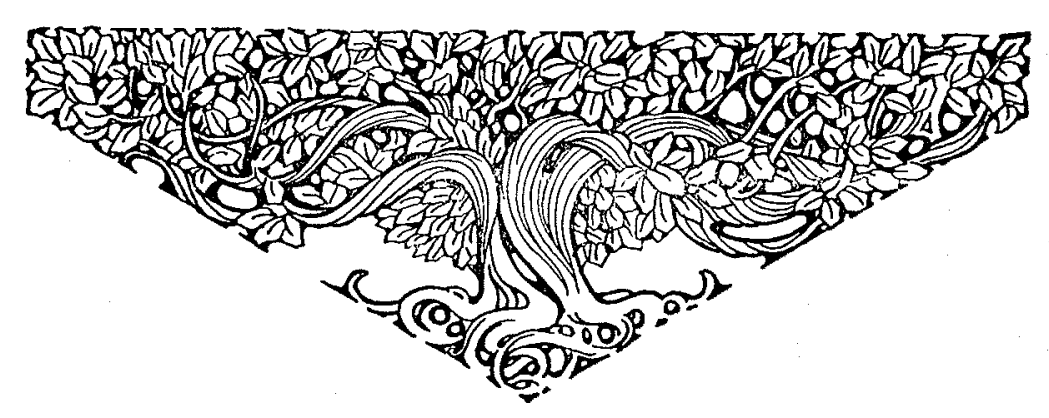

